Article

\title{
Marine Energy Environmental Permitting and Compliance Costs
}

\author{
William J. Peplinski ${ }^{1, *(D)}$, Jesse Roberts ${ }^{1}$, Geoff Klise ${ }^{1}$, Sharon Kramer ${ }^{2}$, Zach Barr ${ }^{3}$, Anna West ${ }^{3}$ \\ and Craig Jones ${ }^{4}$ \\ 1 Sandia National Laboratories, Albuquerque, NM 87185, USA; jdrober@sandia.gov (J.R.); \\ gklise@sandia.gov (G.K.) \\ 2 H. T. Harvey \& Associates, Los Gatos, CA 95032, USA; skramer@harveyecology.com \\ 3 Kearns \& West, San Francisco, CA 94104, USA; zbarr@kearnswest.com (Z.B.); awest@kearnswest.com (A.W.) \\ 4 Integral Consulting, Santa Cruz, CA 95060, USA; cjones@integral-corp.com \\ * Correspondence: wjpepli@sandia.gov
}

check for updates

Citation: Peplinski, W.J.; Roberts, J.; Klise, G.; Kramer, S.; Barr, Z.; West, A.; Jones, C. Marine Energy

Environmental Permitting and Compliance Costs. Energies 2021, 14 , 4719. https://doi.org/10.3390/ en14164719

\section{Academic Editors: Paula}

Fernández González and María José Presno

Received: 18 June 2021

Accepted: 30 July 2021

Published: 4 August 2021

Publisher's Note: MDPI stays neutral with regard to jurisdictional claims in published maps and institutional affiliations.

Copyright: (c) 2021 by the authors. Licensee MDPI, Basel, Switzerland. This article is an open access article distributed under the terms and conditions of the Creative Commons Attribution (CC BY) license (https:// creativecommons.org/licenses/by/ $4.0 /)$.

\begin{abstract}
Costs to permit Marine Energy projects are poorly understood. In this paper we examine environmental compliance and permitting costs for 19 projects in the U.S., covering the last 2 decades. Guided discussions were conducted with developers over a 3-year period to obtain historical and ongoing project cost data relative to environmental studies (e.g., baseline or pre-project site characterization as well as post-installation effects monitoring), stakeholder outreach, and mitigation, as well as qualitative experience of the permitting process. Data are organized in categories of technology type, permitted capacity, pre- and post-installation, geographic location, and funding types. We also compare our findings with earlier logic models created for the Department of Energy (i.e., Reference Models). Environmental studies most commonly performed were for Fish and Fisheries, Noise, Marine Habitat/Benthic Studies and Marine Mammals. Studies for tidal projects were more expensive than those performed for wave projects and the range of reported project costs tended to be wider than ranges predicted by logic models. For eight projects reporting full project costs, from project start to FERC or USACE permit, the average amount for environmental permitting compliance was $14.6 \%$.
\end{abstract}

Keywords: ECCA; marine energy; environmental compliance; licensing; permitting; compliance costs; project development; monitoring

\section{Introduction}

The marine energy (ME) industry (marine energy refers to renewable energy captured from waves, tides, ocean currents, the natural flow of water in rivers, and marine thermal gradients, without building new dams or diversions) has a vital role in the U.S. clean energy strategy as we progress to meet U.S. electricity needs with renewable, domestic energy sources. However, the young U.S. marine energy industry has had few operational projects, which presents multiple challenges for environmental assessment and monitoring. The lack of environmental baseline data and historical databases on potential environmental effects for these new technologies have resulted in high uncertainty regarding potential environmental impacts. This uncertainty presents significant challenges for marine energy developers, who have identified the cost and time for environmental permitting and compliance as a major development hurdle (Copping et al. [1,2]). Overall, the costs of licensing, permitting, and environmental compliance (e.g., environmental monitoring) for marine energy projects have not been well understood or quantified. While efforts have been conducted to look at these costs in similar industries (e.g., offshore wind, offshore oil and gas; Kramer et al. [3]), there has been no comprehensive investigation for marine energy. Previous efforts focused on marine energy have utilized logic models to define and estimate costs. The best documented effort in the U.S. has been the Environmental 
Compliance Module of the Reference Model Project. The Reference Model Project, sponsored by the U.S. Department of Energy, was a partnered effort to develop open-source marine hydrokinetic/marine energy point designs as references to benchmark marine energy technology, performance, and costs. (Copping and Geerlofs, Neary et al. [4,5].) The Environmental Compliance Module theorized what resources were required for the licensing, permitting, and compliance of ME projects based on efforts from other industries as well as from the handful of projects being developed at that time.

The primary goal of the present effort, the Environmental Compliance Cost Assessment (ECCA) project, has been to compile and analyze the available environmental permitting and compliance costs for a variety of U.S.-based marine energy projects that have gone through the permitting process. This first-of-a-kind effort provides a national "snapshot in time" of early marine energy development and understanding of the studies and costs associated with permitting and monitoring, contextualized with overall project costs where available. Our objectives were to:

1. Examine actual cost information for marine energy project permitting, licensing, monitoring, and compliance;

2. Collect additional project information to provide context for those costs;

3. Understand developer and regulatory perspectives on the permitting process.

Comparing cost information from multiple project types at different locations-with different permitting requirements and progress in their permitting process-understandably produced widely variable results and associated challenges for analysis. For example, each project had different experiences complying with federal laws such as the Endangered Species Act, the Marine Mammal Protection Act, the Coastal Zone Management Act, and the Magnuson-Stevens Fishery Conservation and Management Act. Further, different states have their own regulatory requirements. Another major project difference is whether a developer permitted their project to deliver energy to the grid; to connect to the grid, developers must follow the Federal Energy Regulatory Commission (FERC) licensing process, whereas those testing a free-standing system not connected to the grid follow the U.S. Army Corps of Engineers (USACE) permitting process. The FERC licensing process generally requires more time and interaction with regulators than the USACE permit process. This can be related to the larger amount of infrastructure required, like subsea transmission cables and the onshore grid connection. The USACE Nationwide Permit 52 (USACNWP 52, or USACE 52) requires much less detail, and less investment of time and money. It is intended "on a national basis to streamline the authorization of activities that result in minimal individual and cumulative adverse effects on the aquatic environment" (USACE [6]). These USACE permits last for 5 years and work well for individual energy converter test deployments. Fortunately, with all of these variable information needs and requirements, the end goals of licensing, permitting, and compliance provide a baseline from which to interpret the data in this work.

In alignment with our objectives, this work collected quantitative cost information from U.S. marine energy project developers (Figure 1) and qualitative information (e.g., experience-based views and understanding of the time and resources associated with permitting) from both U.S. industry project developers and federal and state regulators to provide data for evaluation. The evaluation was conducted to look for opportunities to create efficiencies in, and improve, the permitting process. The opportunities were modeled after the findings of the work (Kramer et al. [3]) that identified the lessons learned from other similar industries. 


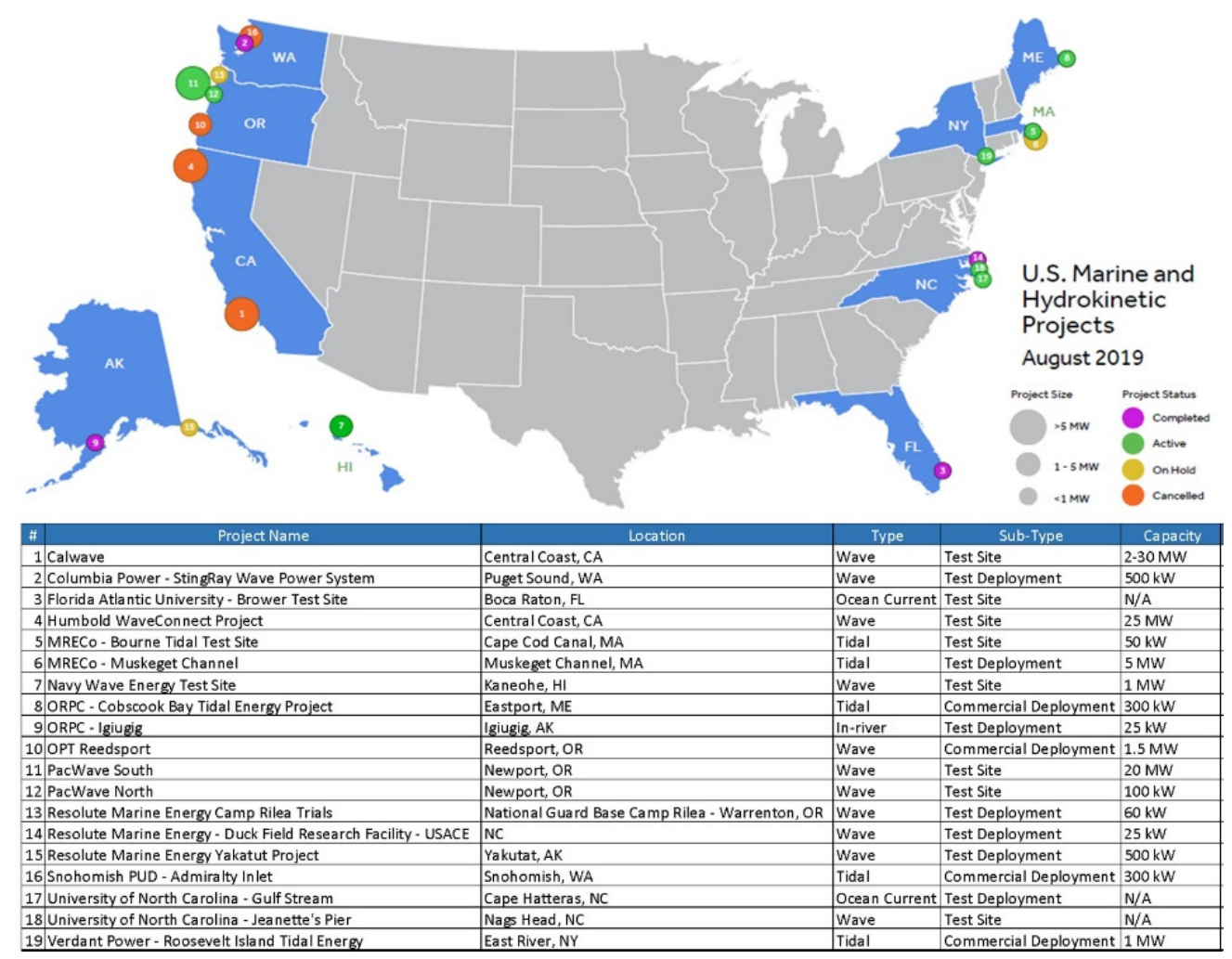

Figure 1. U.S. marine energy developers' project information. Numbering to link project information to location. To protect proprietary data the numbers do not correspond with project numbers in following figures.

The data collected included overall project development costs as well as costs for marine energy licensing and compliance activities, including those associated with environmental studies, stakeholder outreach, baseline studies (pre-project site characterization), mitigation and monitoring, and adaptive management measures. In this article, "monitoring" is defined as a post-installation study that is conducted under a specific standardized protocol that is defined during consultation with permitting agencies during the permitting and licensing process. Although the developers and projects are noted in this paper, all cost data are aggregated to ensure confidentiality and protection of proprietary information. Data on costs and project findings were shared several times over the 3-year data collection period-in workshop environments and through one-on-one interviews- to enable the marine energy community to review and provide feedback on our findings and categorizations, helping to ensure accuracy and digestibility (Figure 2). As part of our assessment, we compare actual cost data obtained and studies required to the baseline of studies proposed and cost estimates offered in the Reference Model work (Copping and Geerlofs, Neary et al. [4,5]). Though not a focus of this paper, the marine energy project permitting and compliance cost data, in coordination with the qualitative, experienced-based regulators and developers' first-hand experience in permitting, were further analyzed to inform pathways that aim to create efficiencies and improve the effectiveness of the permitting and compliance processes. 


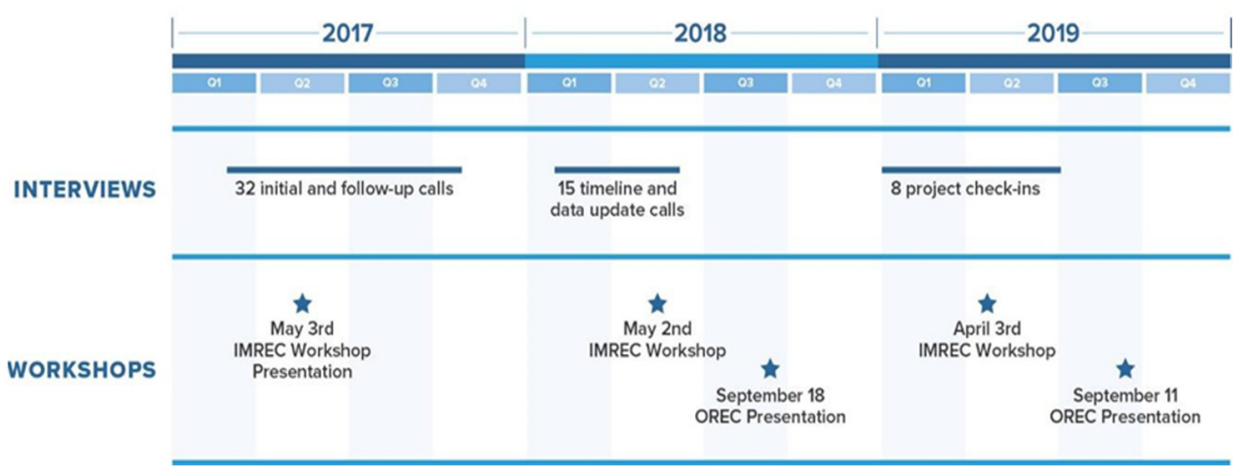

Figure 2. Outreach and engagement schedule.

\section{Scientific Approach}

\subsection{Information Collection}

Given the interest in collecting quantitative as well as qualitative information from project developers, the project team merged qualitative and quantitative research methods and survey techniques (Marsland et al. [7], Busetto et al. [8], Gill et al. [9]), following a modified Convergent Parallel Design [8]. The project team interacted with developers in a semi-structured format (Barrett and Twycross [10]), with specific written quantitative and qualitative questions asked in formal surveys to obtain data, as well as likely process causes of costs (Marsland et al. [7]).

Developer participants were initially engaged to explain the goals of our efforts and gauge their interest in participating and sharing their cost data and overall experience with the marine energy permitting and environmental compliance process. It is important to note that developer participants were offered modest compensation to cover the costs associated with organizing and submitting their data as well as directly interacting with our team on clarifying discussions. There were no limitations, either high or low, on the number of participating developers and projects. Interested parties were asked to complete an electronic survey and cost matrix to provide qualitative experience during environmental compliance, as well as actual cost data. Multiple follow-on guided discussions were held with participants to better understand the context of the information provided in the survey and cost matrix. Federal and state regulators shared qualitative feedback about the process, time, and resources associated with permitting. Regulatory engagement was provided voluntarily.

Overall, 55 guided discussions were conducted with 14 project developers about 19 projects, in three phases from 2017-2019 (Figures 1 and 2). Initial discussions with marine energy project developers, and federal and state agencies, were conducted between March and October 2017. Additional discussions were conducted in 2018 and 2019 to capture up-to-date costs as projects progressed, as well as to clarify the reported cost data, and qualitative feedback. The final phase of discussions focused on sharing our suggested strategies and actions to increase the efficiency and effectiveness of the permitting process and gather feedback on the strategies and actions. The format of the discussions-described by Gill et al. [9] as focus groups - combined ethnography and phenomenological study approaches to best understand the culture, norms, and beliefs of project developers and federal and state regulators, and understand environmental compliance from a developer's and regulator's point of view (Leedy and Ormrod [11]). Guided discussions were moderated and facilitated (Williams [12], Gill et al. [9]) to maintain objectivity, reduce conflict, and scribe notes. Clarifying questions were asked on the data information collected such as specific methodology of a required study or additional detail on how documentation was prepared. Open-ended questions focused on understanding perceived barriers to permitting/licensing efficiency, cost-saving resources, technical challenges and information gaps, ranges of costs, opportunities to improve the permitting/licensing efficiency, and 
other permitting lessons learned. Both project developers and federal and state regulators participated in the qualitative discussions.

Feedback was also collected at group workshops and webinars over the life of the project (Figure 2). We presented progress with our analysis and results at meetings following the International Marine Renewable Energy Conferences (IMREC) in Washington, D.C. (3 May 2017, 2 May 2018, and 3 April 2019), at the Ocean Renewable Energy Conferences (OREC) in Portland, Oregon (18 September 2018, and 11 September 2019), and through webinars for regulators and developers (12 June 2018, and 12 June 2019). These workshops and webinars were attended by marine energy developers and state and federal agencies providing a forum to gather feedback on work products and next steps. Workshops and webinars were facilitated to reduce potential conflict (O'Leary and Bingham [13]) between regulators and developers, as well as focus the group during discussions.

Interviewee Selection

Project developers were identified through licensed marine energy projects, active marine energy project's preliminary permit, and pending marine energy project permit resources on the official Federal Energy Regulatory Commission (FERC) website. Additional resources such as the U.S. Department of Energy (DOE) reports and additional web research were used to find historical and inactive projects. The selection of project developers was limited by available contact information, whether the company was still in existence, and the project developer's capacity to participate.

For some projects, environmental studies were performed by multiple entities (most notably universities and national laboratories) with funding coming from multiple sources (e.g., DOE, National Science Foundation, state trusts, etc.). These factors were known to the authors due to the authors' familiarity with marine energy development history but were often not directly tracked by the marine energy project developers (and hence not always included in their responses). In these instances, the team reached out to the Principal Investigators (PIs) who performed the complementary studies to get further clarification on external funding sources and amounts that were specifically used to develop study plans, conduct pre-installation site characterization used for license or permit development, and conduct post-installation compliance monitoring. In each case, we asked that the PI only provide costs of work conducted as a requirement by federal and state regulators for permitting or environmental compliance of projects.

There were several tools used to collect information from interview participants, including an electronic survey instrument and cost matrix.

The electronic survey instrument was used to guide discussions with developers and included a series of open-ended questions focused on collecting information related to general project background, the planning process, permitting pathway, environmental concerns, post-licensing experiences, and recommendations (Table 1). With sub-questions under the main headings there were a total of 63 qualitative questions. These topics provided additional context to the quantitative information collected by the cost matrix (Marsland et al. [7]).

The cost matrix was a 65-line spreadsheet with questions organized into licensing costs and post-licensing costs. Time spent (in days), actual costs, non-labor costs, funding sources, budgeted costs, other costs not covered, confidence, challenges, and regulatory authority were collected. The permitting phase and various cost subcategories collected in the matrix, including baseline information study costs, are shown in Table 2. Additional information such as outside funding contributions and timeframes for preliminary, draft, and final license applications was also collected. 
Table 1. List of survey instrument topics and subtopics.

\begin{tabular}{|c|c|}
\hline Topic & Subtopic \\
\hline \multirow{7}{*}{ General Background } & Goals of the project \\
\hline & Capacity (megawatt [MW], kilowatt [kW]) \\
\hline & Staffing \\
\hline & Challenges and Expectations \\
\hline & Success of Permitting \\
\hline & Regional Initiatives and Their Impact \\
\hline & Role of State and Federal Agencies \\
\hline \multirow{5}{*}{ Planning Process } & Use and Support of Existing Information or Entities \\
\hline & Cost Expectations \\
\hline & Efficiencies in Meeting Environmental Compliance \\
\hline & Planning Tools and Their Use \\
\hline & Understanding of Environmental Requirements \\
\hline \multirow{5}{*}{ Permitting Pathway and Licensing Process } & Federal Energy Regulatory Commission (FERC) Permitting Pathway \\
\hline & Expected Timeframe for Permitting Phases \\
\hline & Expensive or Time-consuming Studies \\
\hline & Outreach and Engagement Process \\
\hline & Innovations \\
\hline \multirow{4}{*}{ Environmental Interactions } & Mitigations \\
\hline & Thresholds (if used) \\
\hline & Monitoring \\
\hline & Development Process and Associated Challenges \\
\hline \multirow{5}{*}{ Post Licensing Experiences } & Construction \\
\hline & Operations \\
\hline & Agreements \\
\hline & Outreach \\
\hline & Decommissioning \\
\hline \multirow{3}{*}{ Recommendations } & Lessons Learned \\
\hline & Information Gaps \\
\hline & Existing Resources \\
\hline
\end{tabular}

Table 2. Cost matrix data collection.

Phase

Permitting and Licensing

\section{Cost Subcategories}

Agency Coordination

Stakeholder and Community Engagement

Environmental Baseline Information Collection

Other Licensing Costs

Documentation

Tasks 
Table 2. Cont.

\begin{tabular}{|c|c|}
\hline Phase & Cost Subcategories \\
\hline \multirow{4}{*}{ Post-license Compliance } & Construction Monitoring and Adjusted Actions \\
\hline & License Operations Compliance Costs \\
\hline & Decommissioning \\
\hline & Other Costs \\
\hline
\end{tabular}

\subsection{Analysis}

Once data collection was completed in 2019, data were organized into categories and subcategories. The primary data categories include resource harvested, project status, project type, basic information, and permit sought. The resource harvested category comprises wave, tidal, ocean, and river current subcategories. The project status category includes active, on-hold, cancelled, and complete subcategories, as of 2019, while the project type category is organized into commercial deployment, test sites, and test deployment subcategories. Commercial deployments are those projects designed to be grid connected with the intent of providing power for communities. Test sites in this work describes locations permitted for short deployments of energy converters to study their behavior and efficiency. They may have multiple berths to handle more than one device at a time and may have monitoring buoys or cabling to shore. Test deployments are projects undertaken by a developer to test the design of an individual energy converter. These are short termwith the time in the water less than a year-and have no connection to the electrical grid. A test deployment may happen at a test site. Basic project information includes location, grid connection, permit initiation date, and regulatory jurisdiction subcategories. The final category, permit sought, includes FERC license, USACE permit, Bureau of Ocean Energy Management lease, and state permits. Data categorization helps to portray the differences or similarities in marine energy projects to allow for proper comparison of project costs.

Environmental study and monitoring compliance cost data were compiled into the categories based on Copping et al. [14], existing permitting documents, information provided during the interviews, and categories used in European approaches (Table 3). Due to location and technology differences (e.g., wave versus tidal), not all projects were required to perform the same studies. Further, there are only a few marine energy projects licensed and deployed, thus one of the challenges during analysis of the cost information was to aggregate the data in a logical and consistent manner. As an example, information was requested for several study categories, but only seven environmental study categories (Table 3) had sufficient information to do further evaluation. Other categories, not listed in Table 3, are reported here but only as a single datum, for which comparisons are difficult. Costs for archeological studies are not reported as they were considered poor estimates by the project PIs. Similarly, we do not report the budget estimates for decommissioning in projects that never went into the water. We chose not to normalize the cost data by inflation or attempt net present value calculations for long term projects. We assume in this work that the relationships between projects would remain essentially the same and the conclusions of the paper would not change. 
Table 3. Environmental study and monitoring and compliance categories and definitions for marine energy projects.

\begin{tabular}{|c|c|c|}
\hline Study Type & Permitting/Licensing Activities ${ }^{i}$ & $\begin{array}{c}\text { Monitoring \& Compliance } \\
\text { (Post-Permitting/Licensing Requirements) ii }\end{array}$ \\
\hline Avian & $\begin{array}{l}\text { Evaluates the presence/absence of seabird } \\
\text { species in the project area. }\end{array}$ & $\begin{array}{l}\text { Evaluates the presence/absence, avoidance, } \\
\text { attraction, collision, or roosting of seabird } \\
\text { species around the deployed device(s) and } \\
\text { infrastructure and evaluates proposed } \\
\text { mitigation measures. }\end{array}$ \\
\hline Collision & $\begin{array}{l}\text { Assesses whether any marine species may be at } \\
\text { risk for collision with a device or infrastructure } \\
\text { being tested, or under full operation and can } \\
\text { include use of computer simulations/models. }\end{array}$ & $\begin{array}{l}\text { Assesses actual collision with or avoidance of } \\
\text { animals in proximity to deployed device(s) and } \\
\text { infrastructure and can be done to validate } \\
\text { simulation/model results. }\end{array}$ \\
\hline Fish and Fisheries & $\begin{array}{l}\text { Confirms the presence/absence of fish and } \\
\text { invertebrate species in the desired deployment } \\
\text { or test area. This includes using hydroacoustics, } \\
\text { netting, traps, and other gear. }\end{array}$ & $\begin{array}{l}\text { Confirms the presence/absence and/or } \\
\text { avoidance/attraction behavior of fish and } \\
\text { invertebrate species in the existing deployment } \\
\text { or test area. This includes using } \\
\text { hydroacoustics, netting, remotely operated } \\
\text { vehicles (ROV), traps, and other gear. }\end{array}$ \\
\hline Marine Habitat & $\begin{array}{l}\text { Includes a wide array of activities at a test or } \\
\text { deployment site, including the use of } \\
\text { bathymetric analysis for determining seafloor } \\
\text { elevation, determining the benthic sediment and } \\
\text { infauna, scouring (sediment transport), } \\
\text { geotechnical seabed (for anchoring and } \\
\text { transmission cabling), and water quality. }\end{array}$ & $\begin{array}{l}\text { Compares pre-project conditions with } \\
\text { post-deployment conditions. }\end{array}$ \\
\hline Marine Mammal & $\begin{array}{l}\text { Determines the presence/absence and seasonal } \\
\text { distribution of marine mammals in the desired } \\
\text { deployment or test area to analyze potential } \\
\text { construction and operation impacts. This } \\
\text { includes using vessels, airplanes, or passive } \\
\text { acoustics to aid in the identification. }\end{array}$ & $\begin{array}{c}\text { Determines the presence/absence and seasonal } \\
\text { distribution of marine mammals in the active } \\
\text { deployment or test area post } \\
\text { deployment/installation. This includes using } \\
\text { vessels, airplanes, or passive acoustics to aid in } \\
\text { the identification. }\end{array}$ \\
\hline Noise & $\begin{array}{l}\text { Determines the potential acoustic impacts from } \\
\text { the operating device(s) and infrastructure by } \\
\text { measuring the pre-project ambient } \\
\text { noise conditions. }\end{array}$ & $\begin{array}{l}\text { Measures the operating noise conditions } \\
\text { compared to pre-project ambient conditions } \\
\text { and evaluates if regulatory thresholds for } \\
\text { marine mammals are being exceeded. }\end{array}$ \\
\hline Terrestrial Habitat & $\begin{array}{l}\text { Determines if there are any wetland or biological } \\
\text { impacts from construction activities due to } \\
\text { trenching for cables and generation tie to } \\
\text { transmission facilities. }\end{array}$ & $\begin{array}{l}\text { Determines if there are any wetland or } \\
\text { biological impacts from the post-license } \\
\text { construction activities, including impacts on } \\
\text { potential turtle or shorebird nesting sites, and } \\
\text { monitors to evaluate if mitigation is effective. }\end{array}$ \\
\hline
\end{tabular}

$\mathrm{i}$-These studies are intended to establish baseline conditions and observations for both marine and terrestrial habitat and species prior to marine energy device deployment and construction activities. ii-These studies are looking for changes to baseline conditions from studies conducted during the permitting/licensing phase, which would happen during project construction and long-term operations.

\section{Results}

The question of how much of total project cost is dedicated to environmental permitting compliance is addressed in Figure 3. Small projects, less than USD 5000, spent up to $25 \%$ of costs on environmental compliance whereas percentages decrease to $10 \%$, or less, as projects increase in size up to USD 50 million. Only eight of the 19 sites reported a value for total cost allowing this calculation. The average percent of these eight is $14.6 \%$. All of these projects successfully finished the permitting process. Additionally, of note, that these data are only a snapshot in time because one data point represents an active, non-deployed project that will continue to incur costs for production, monitoring, and compliance. If that site is removed from the calculation, the average percent increases to $14.9 \%$. 


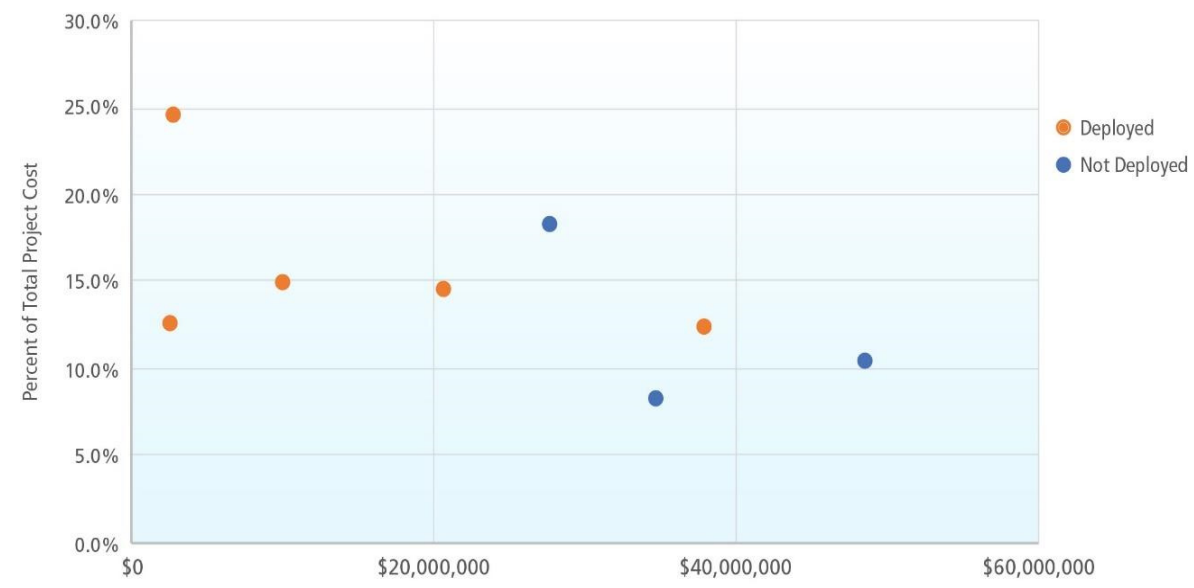

Figure 3. Percentage of environmental compliance cost of total project.

We compared the total environmental compliance cost of the projects, which included the total non-capital expenditures, with permitted production capacity of the analyzed commercial, test deployment, and test site projects (Figure 4). The total non-capital expenditures for each project is the sum of the permitting/licensing costs, monitoring/compliance, and other costs (engineering, design, etc.).

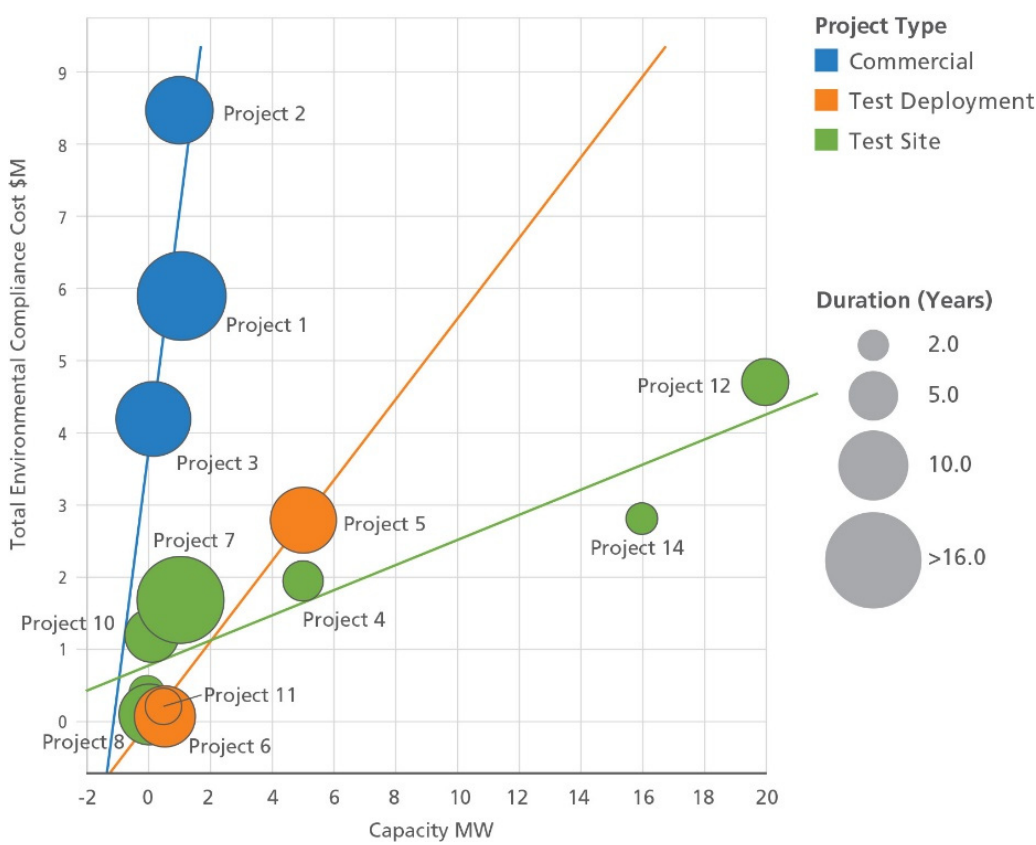

Figure 4. Permitted Capacity vs. Total Environmental Compliance Cost.

The data for each project type were fit with a simple trendline to depict the general relationship between project types (e.g., commercial, test sites, and test deployments). Commercial projects are the most expensive and have relatively small production capacities due to their small scale. Capacities are anticipated to increase as the industry matures. Test sites have lower costs and some of them have been permitted with higher capacities. Test deployments have the lowest costs and have low permitted capacities, being clustered near the origin on Figure 4, with the exception of Project \#5.

The largest permitted capacity of the three commercial projects is $1.05 \mathrm{MW}$ and has the highest total cost at USD 8.5 million (Figure 4). All three commercial projects are tidal projects, and two are still in operation or development. One was terminated by the developer. Project duration ranged between 9 and 17 years at the time of data collection, suggesting considerable commitment by the project developers. 
There is much more variability in test site project duration than that of the commercial sites, ranging from 3 to 16.7 years. The two longest project durations (i.e., the largest green circles in Figure 4, Projects \#7 and \#8), did not incur the highest costs as they had relatively simple regulatory paths; our qualitative data suggest that of the three largest capacity test sites, two are no longer active (Projects \#4 and \#14), but five of the test sites represented in Figure 4 are either active or in active development.

Test deployments are all clustered around the origin (Figure 4, orange circles) with the exception of Project 5, a tidal project. Note that the environmental compliance cost for the tidal project is greater than that of the wave projects.

Environmental study costs for seven wave and five tidal projects, including wave project test sites, wave test deployments, and tidal projects (commercial and test deployments) were compared by study type (Figure 5). Not all of the projects were required to perform the same studies but these seven study categories allow comparison. The most commonly performed environmental studies were: Fish and Fisheries (9), Noise (9), Marine Habitat/Benthic (9), Marine Mammals (6), and Avian = (4).

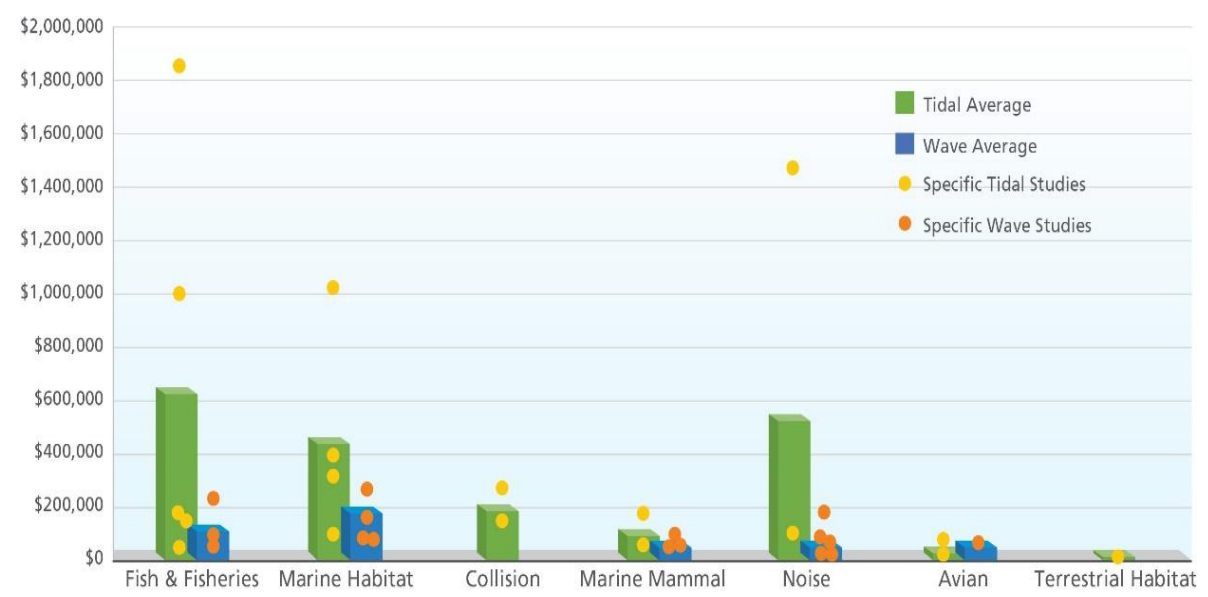

Figure 5. Comparison of environmental study costs by study and project type.

Study costs for tidal projects were generally more expensive than wave, which may be due to higher perceived environmental risks, differing environmental conditions, and uncertainties. The tidal projects category includes long-term commercial projects and challenges to monitoring in high-velocity tidal habitats (Figures 4 and 5). The paucity of published studies in high-energy tidal environments leads to a general lack of knowledge and higher regulatory uncertainty (Sparling et al. [15]), therefore increasing costs of baseline studies.

Further, the tidal projects presented are predominantly commercial deployments ( 3 of 5), which may also result in increased costs compared to the wave test sites and test deployments (there are currently no U.S. wave energy commercial deployments). Fish and Fisheries, Marine Habitat, and Noise studies are the largest average expenditures for both tidal and wave projects. For wave test deployments the only studies conducted were for Noise, suggesting that evaluating device noise is an important requirement for regulatory agencies.

Three tidal projects (Projects 6, 8, and 19) studied fish species behavior and distributionto inform possible interactions with the tidal turbines. These Fish and Fisheries studies conducted for tidal projects are the most expensive study category, with their percentages of total permitting and licensing costs ranging from $7 \%$ to $75 \%$.

Environmental studies done for post-deployment device monitoring and compliance were evaluated for three wave and three tidal projects (Figure 6). Wave and tidal projects did not always conduct the same post-deployment monitoring and compliance studies, but noise, adaptive management, and marine habitat studies were conducted for both. Collision study costs, incurred by the three tidal projects, had the highest cost average and 
variability. The highest cost Collision study is not shown in Figure 6 because its value at USD 2.9 million is an outlier; including it raises the Collision study average value from USD 421,000 to USD 1.257 million. This one high value is from permit-required monitoring that necessitated high research and development costs to pioneer study methods and instrumentation. These costs were borne by the developer and DOE, but the research (e.g., new methods and instrumentation) will contribute to reduced costs in the future. Certain studies (e.g., Recreation and Avian) had lower costs.

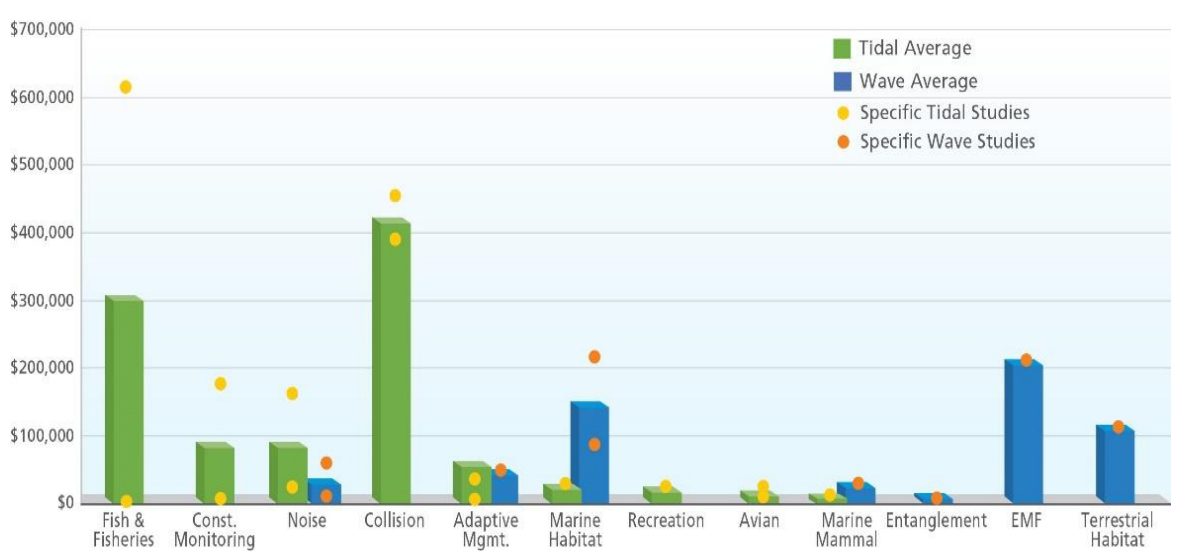

Figure 6. Comparison of post-installation environmental study costs.

The three highest cost categories for tidal projects were Fish and Fisheries, Collision, and Noise. As a percentage of the project costs for post-installation studies, these categories averaged $52 \%, 58 \%$, and $9 \%$, respectively. The three highest environmental study costs for wave projects were Electromagnetic Fields (EMF), Marine Habitat, and Terrestrial studies to support onshore grid connection. Again, as a percentage of the project costs for post-installation studies, they averaged $57 \%, 39 \%$, and $32 \%$, respectively.

Environmental studies in support of permitting were costlier on average for Fish and Fisheries and Marine Habitat studies conducted for projects on the East Coast compared to projects on the West Coast (Figure 7). This is likely because East Coast projects are mostly tidal, which, as discussed above, have greater environmental uncertainties and are typically more expensive to evaluate in general. Costs for Noise studies were higher for West Coast projects than East Coast projects and that trend is maintained when considering project percentage. Several smaller studies spent $100 \%$ of their permitting budget on noise studies, driving the averages to $35 \%$ on the East Coast and $51 \%$ on the West Coast.

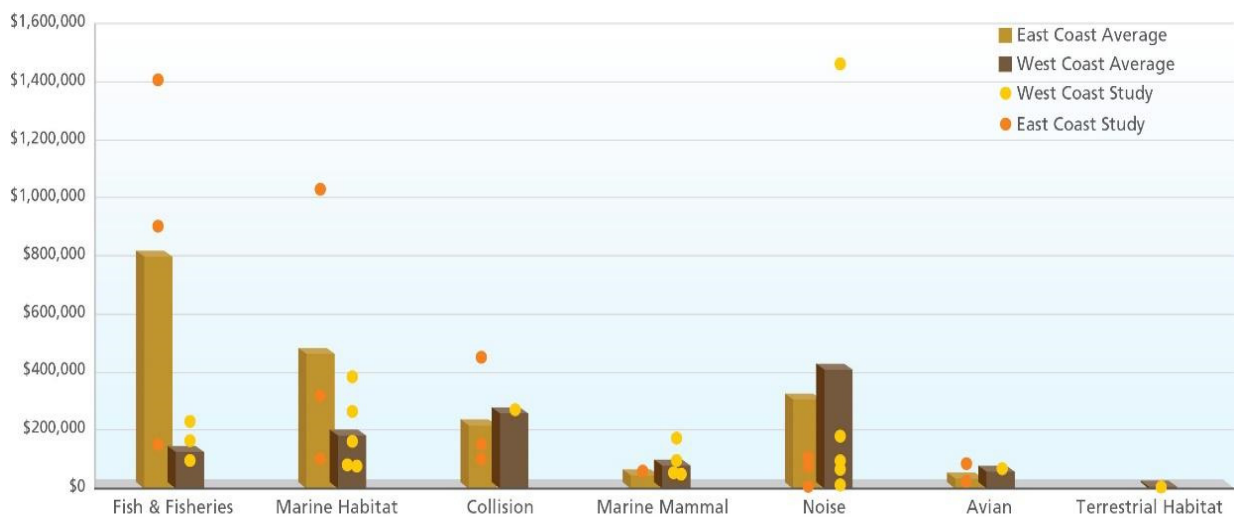

Figure 7. Geographic differences in environmental study costs, East vs. West.

Costs for meetings and public outreach were considerable for several projects as well, as shown in Figure 8. 


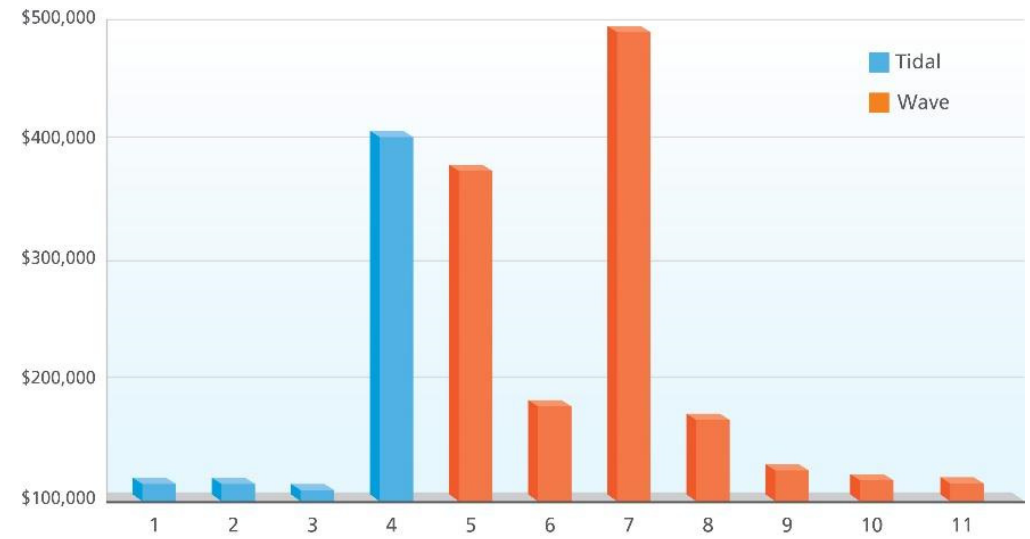

Figure 8. Outreach costs by energy type.

Analysis of outreach spending suggests that wave projects spend more on public interaction than tidal energy projects. Project funds spent on public outreach and education varied from USD 8000 to USD 500,000, with 11 of the project efforts reporting, but just four sites spent between USD 84,000 and USD 500,000. There could be several reasons for the tendency of high cost wave projects. Wave projects may have a larger footprint and therefore a greater interaction with local fisheries. Wave projects are typically moored to the bottom, raising the perceived risk of entanglement or entrapment of cetaceans, and there may be local concerns about EMF due to long export cables running along the bottom from arrays anchored farther offshore.

Sources of funding changed over time for 10 ME projects, with data reported in 2019 (Figure 9). Project compliance duration in years is shown as the number below each bar. The longest duration projects received a majority of their funding for environmental permitting costs from private developers, with some federal and state support. More recently, a much higher percentage of state and federal funding was used to support permitting, as is seen specifically in the case of the 5.4-year test site. The range of funding varies widely for these sites, between USD 4000 and USD 5 million, reflecting the differences between commercial sites and short-term test deployments. The shortest duration project (60 days), was 100\% developer funded for USD 4000. The two longest duration projects (12.2 and 17 years) have used between USD 2 million and USD 3.5 million in developer funds.

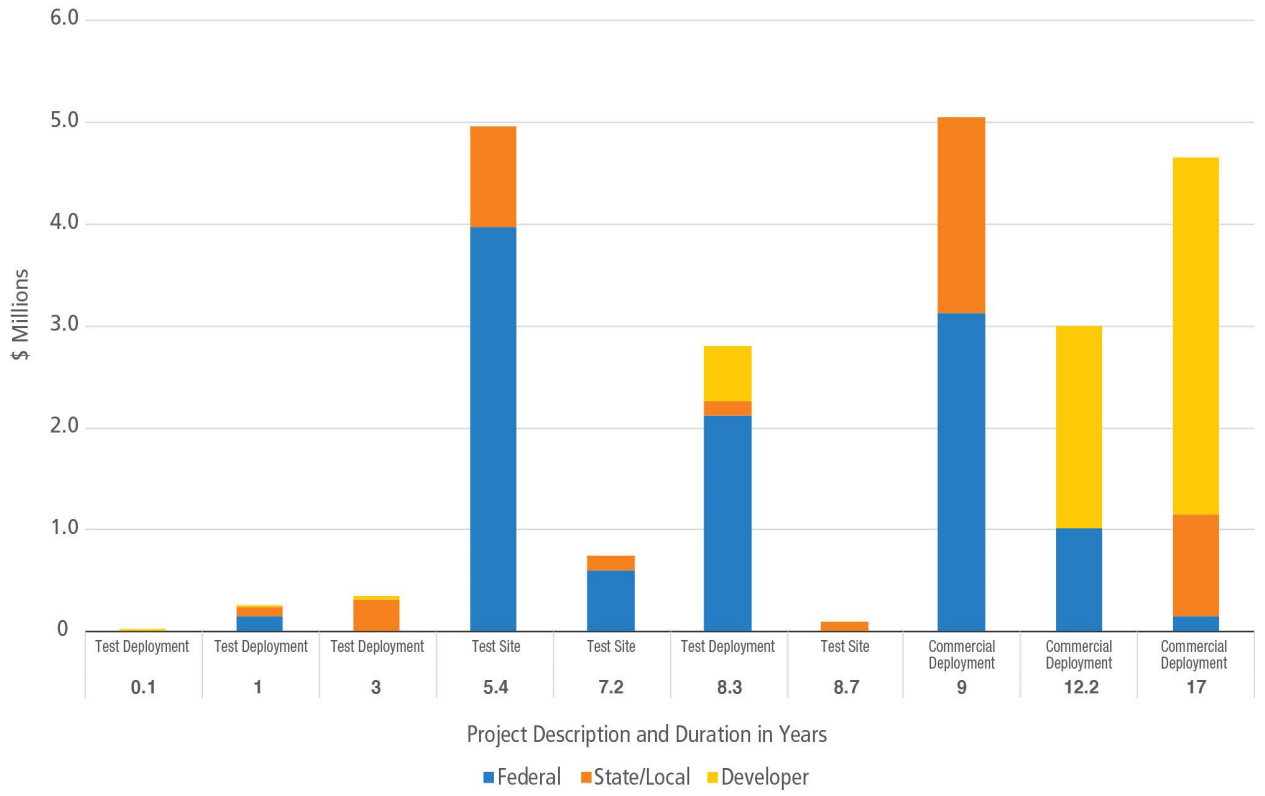

Figure 9. Environmental permitting costs by funding source. 


\section{Comparing Actual Project Data to Reference Models}

In 2011, Pacific Northwest National Laboratory published benchmark estimates of how environmental siting and permitting requirements contributed to the cost of wave and current/tidal based Marine Renewable Energy (MRE) installations (Copping and Geerlofs [4]). The goal was to "identify key cost drivers and cost reduction pathways to direct future R\&D efforts." Logic models were developed to describe expected studies and provide a range of siting and permitting costs from pilot to small and to large commercial scales. Cost estimates in these reference models were developed based on previous and proposed projects, scaling factors, projections for post-installation monitoring costs, and expert opinions. A range of costs was given (Copping and Geerlofs [4]) as an acknowledgement of the large amount of uncertainty in their calculations. Estimates were placed in the categories of Siting and Scoping, Pre-Installation Studies, Post-Installation Studies, and NEPA and Process. Reference Model 1 (RM-1) estimates costs for a tidal site, based on Puget Sound resource data. Reference Model 2 (RM-2) estimates permitting costs for riverine technology and Reference Model 3 (RM-3) estimates costs for a wave energy site, based on resource data from Northern California.

Neary et al. [5], Bull et al. [16], and Yu et al. [17] provided additional costing benchmarks. They incorporated and expanded on the earlier Reference Models in analyses to estimate the levelized cost of electricity (LCOE) from MRE devices. Their six reference models each contain four modules to cover capital and operational expenditures (CAPEX and OPEX): Design and Analysis Module; Manufacturing and Deployment Module; Operations and Maintenance Module; and Environmental Compliance Module. Similar to Copping and Geerlofs [4], estimates are made at multiple scales: a single energy converter, a small array of 10 units, a larger array of 50 units, and the largest array of 100 units. The same binning categories mentioned above are used in the Environmental Compliance Module. Wave and tidal energy characterizations for (Neary et al. [5]) RM-1 through RM-3 correspond with Copping and Geerlof's [4] RM-1 though RM-3. Neary's RM-4 covers new ground describing an ocean current turbine. RM-5 (Yu et al. [16]) describes an oscillating surge wave energy converter (WEC) and RM-6 (Bull et al. [17]) an oscillating water column energy converter.

Our actual tidal and wave project costs are compared to both of the models for RM-1 (Figure 10) and RM-3 (Figure 11), respectively. Copping and Geerlof's [4] pilotscale estimate more closely matched the actual data as they represent mainly pilot-size installations, particularly the tidal energy converters (TEC) in Figure 10. None of these data yet represent small or large commercial installations. Figure 11 represents costs for WEC test deployments and test sites. Three of the four size ranges considered by Neary et al. [5] are shown in both figures, 1, 10 and 50 energy converters.

Figures 10 and 11 suggest that, at this point in time, environmental compliance costs are variable beyond the ranges estimated by the Reference Models. In two categoriesSiting and Scoping and Post-Installation Studies (Figures 10 and 11) - the average values generated from the data are above Copping and Geerlofs' [4] model results. In other cases (Figure 11, Pre-Installation Studies) the average data value is below the model results. Comparison to Neary et al.'s [5] model results suggests a similar pattern, with the average data value below the single WEC cost estimates (Figure 11, Pre-Installation Study) and most others above the values for a single WEC with some above the 50 WEC installation estimate. Multiple outlier points are beyond the cost estimates for a $50 \mathrm{WEC} / \mathrm{TEC}$ array, which bring the average values up. 


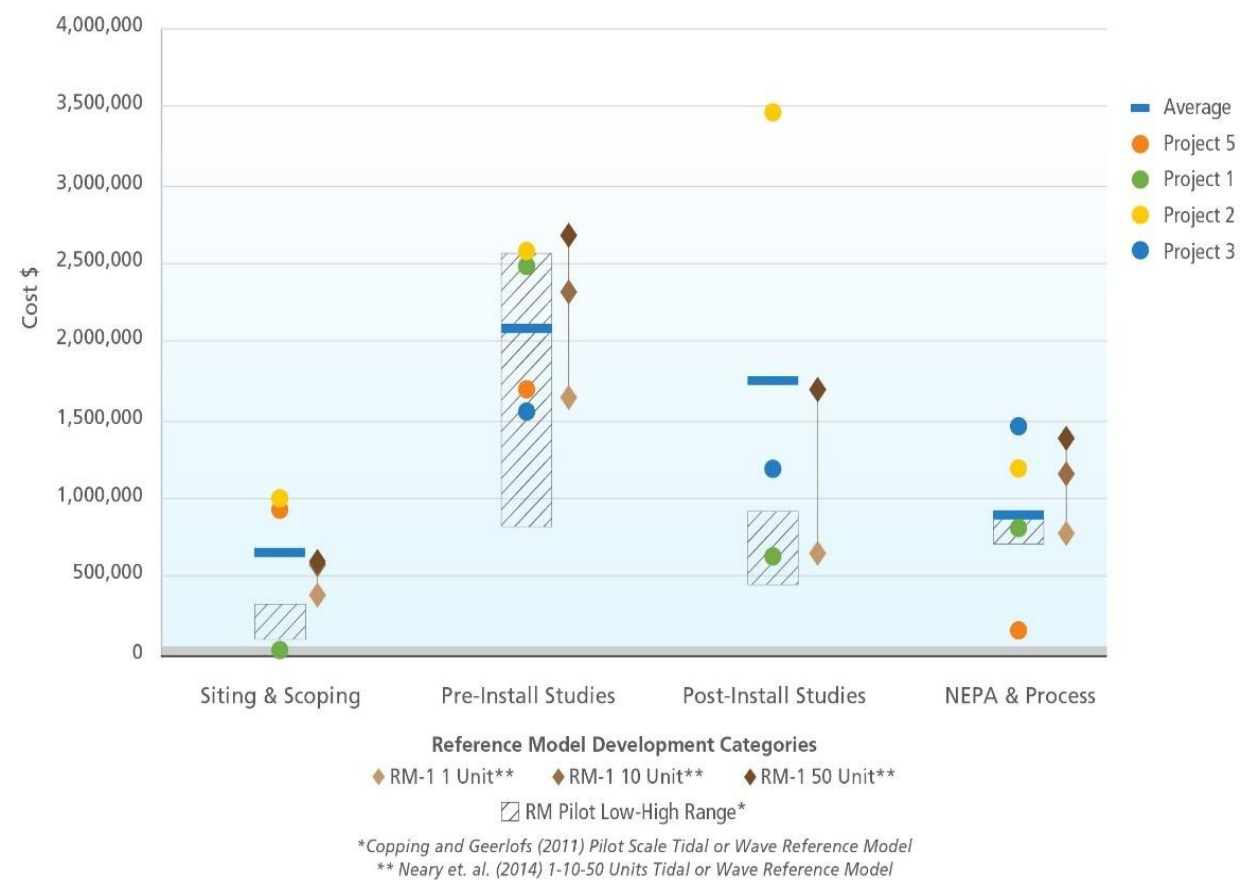

Figure 10. TEC Reference Model comparison.

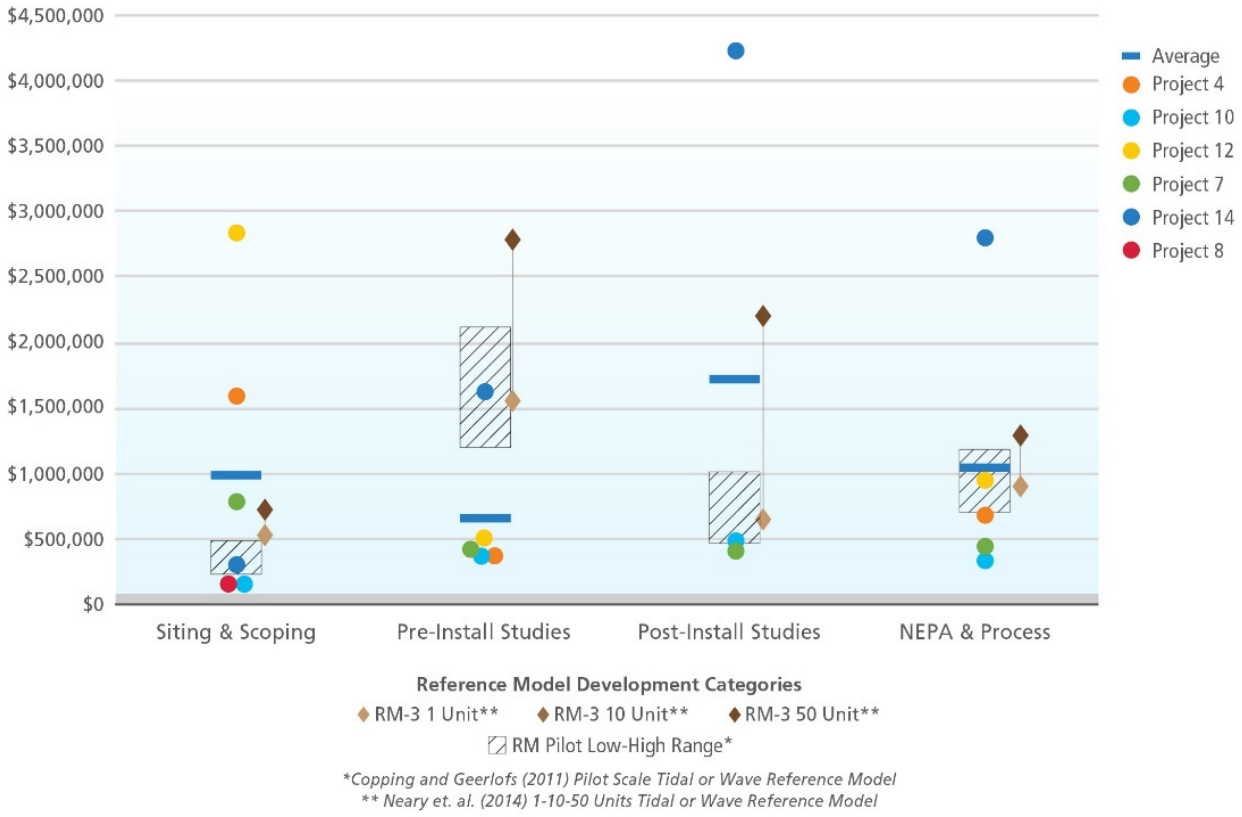

Figure 11. WEC Reference Model comparison.

\section{Discussion}

Using cost information from multiple project types, at different locations and scales, with different permitting requirements and levels of progress in their permitting process, creates difficulty in comparing dissimilar data. All these differences lead to the range of data values reported.

The differing permitting pathways of FERC for grid connected projects and USACE for non-grid connected projects were mentioned earlier. As an example of this variability consider two projects that may both report doing a fisheries study, with one following the FERC licensing process and the other following the USACE process. The first may have had multiple phases and field efforts taking several years, whereas the second may have 
been completed with a literature search over less than a year. Thus, the final cost of these two studies will be quite different.

Projects were also in different stages of development during this study. For example, considering Capacity vs. Total Cost (Figure 4), the total costs reported will continue to increase for the active projects while a completed projects' costs will remain static. Several of the test sites, in particular, are still working towards a final permit and their costs continue to grow. Similarly, for active permitted sites their total costs continue to grow as they continue monitoring and compliance activities. Thus, these data are merely a snapshot in time of compliance costs in the development of a new energy technology.

Equally important is that WECs, TECs, and current energy convertors (CECs), unlike wind turbines, are not built to a standardized design, leading to multiple unknowns in the regulatory process. Each new design must be considered in terms of the associated environmental stressors with no benefit from previous lessons learned, because they will not apply to a totally different design. Thus, the distribution of costs is wider than estimated in the Reference Model work (Figures 10 and 11).

Finally, some of the differences between project costs may come down to the comfort regulators have with MRE technologies and developers. Previous experience and development of good relationships between MRE developers and regulators may lead to a level of trust, smoothing the initial application process and later adaptive management decisions. Conversations during guided discussions suggest this can be the case.

As noted, the most commonly performed environmental studies were Fish and Fisheries, Noise, Marine Habitat/Benthic, Marine Mammals, and Avian Studies (Figure 5), with greater costs for environmental studies for current energy projects than for wave energy projects (Figures 5 and 6). Guided discussions with developers suggest this is because it is much more difficult and expensive to collect data in a high-energy tidal environment than in a wave energy environment. Under the known episodic high flow rates experienced in tidal channels, collecting data underwater may be either limited to short work windows (e.g., during slack tides), or longer work windows with higher instrumentation costs. Many instruments are not "off the shelf" but under research and development, which may drive up study costs compared to wave energy sites.

Baseline studies are also less common in high-energy environments. Often it is only known that fish species may be present, but their use of tidal channels during different tidal cycles, day vs. night, and different seasons, is poorly understood. As a result, it is generally not known which species or how many individuals might come into contact with a tidal turbine, especially when it is rotating during fast tidal flow. This has led to a perception amongst some stakeholders of higher risk, predominantly to commercial fish species. Therefore, fish and fisheries studies (Figures 5 and 6) are needed to determine which species are present, timing and duration of site use, and exposure to tidal turbines. Collision studies are using video systems, acoustic cameras, and stationary and mobile hydroacoustics to determine if fish collide with rotating blades or are able to detect and avoid them, to improve understanding of risks (Viehman and Zydlewski [18], Sparling et al. [15], Polagye et al. [19]).

The outlier data point for tidal collision monitoring (USD 2.9 million) represents funding used to develop instrumentation such as remote undersea optical and acoustic cameras, lighting systems, and other integrated instrumentation, to observe fish in the vicinity of turbine blades (Sparling et al. [15], Polagye et al. [19]). Permitting of one project was dependent on the ability to characterize and validate the risk of juvenile salmon and marine mammal collision with tidal turbines at the site. As technology was not available at the time, DOE funded research and development to create and test instrumentation. Though a high cost for project development, this technology is now available for use by other projects.

When comparing environmental study costs based on location (East vs. West Coast, Figure 7), the East Coast tidal projects have the highest costs with Fish and Fisheries and Marine Habitat studies, with average values of USD 800,000 and USD 450,000, respectively. 
On the West Coast, projects' highest costs are for Acoustic/Noise and Collision studies, but average values are still well below the East Coast for Fish and Marine Habitat studies. These data indicate that studies of fish and their habitat are more expensive than marine mammal acoustic studies.

Comparing wave and tidal energy outreach costs suggests wave project developers focused more on public interaction. One tidal project did spend more than all but one wave project (Figure 8, Project 4), having conducted over 100 formal and informal meetings with upwards of 50 stakeholder groups over a 5-year period. There are multiple reasons for increased outreach and interaction costs for wave projects; they are located predominantly on the West Coast, increasing the potential for development to affect valuable commercial and recreational fisheries such as Dungeness crab and Chinook salmon, and the potential for interactions with a number of species listed under the Endangered Species Act, such as Southern Resident killer whales, listed salmonids, and green sturgeon.

The projects, compared by funding source (Figure 9), are ordered from shortest to longest duration but they are also roughly in chronological order by start date. A few are out of order, but the general trend is clear: longer running and older projects have used more private developer money. Shorter and more recent projects have been more fully supported by state and federal funds. The exception is the shortest project in Figure 9, with a duration of 0.1 year. This project was funded entirely with developer funds and may represent any number of small un-reported experimental deployments that would rather focus on engineering than grant applications. Lack of funding is often the greatest obstacle for developers and increased support from government bodies over time bodes well for this young industry.

The Logic and Reference Models developed for DOE by Copping and Geerlofs [4] and Neary et al. [5] represent expert knowledge and engineering cost predictions for use in scoping ME projects. Actual data indicate that costs vary well beyond predictions. Data collected in the interview and survey process revealed environmental studies for several projects turned out to be more expensive and some less expensive than predicted. Figure 11 shows examples of each. In the Siting and Scoping category, one test site reported costs over 3 times greater than those expected for a 50 WEC array. Yet, in pre-installation studies the same site reports study costs well below the lowest Reference Model estimate. This is partially explained by site-specific difficulties with studies, longer time for data collection required than expected, or more complex monitoring required to obtain baseline information to support permitting. Obviously, much is still unknown. Pathways to decrease these costs and improve efficiencies in permitting will be the goal of a follow-on article.

\section{Conclusions}

Over the last two decades, which our data represents, permitting of marine energy projects has proven to be a challenge as the nascent industry strived to develop the technology to tap the potential of ocean energy. Marine energy's nearshore location and unique, developing technologies have led to increased scrutiny and greater permitting and monitoring costs. This likely represents the initial steep section of the learning curve for permitting projects, with costs expected to decrease as stakeholders gain better understanding of its environmental effects and benefits, and the preferred technologies narrow.

The most expensive environmental studies conducted were for Fish and Fisheries, Noise, and Benthic Habitat and were reported for 53\%, 65\% and 53\% of the projects, respectively. Studies done for tidal installations were more expensive than for wave installations, with average values 4.8 times greater for Fisheries, 3 times greater for Marine Habitat and 7 times greater for Noise. The range of study costs was also wider than predicted by the previous estimation models of Copping and Geerlofs [4], and Neary et al. [5], for both tidal and wave projects. As more projects progress through the permitting process and into construction and operation, improved instrumentation and standardized monitoring protocols and technologies will likely lead to a decrease in cost of permitting. Future research on permitting costs, compared with those reported here, would be the best way to 
document those results. Lessons learned from projects suggest that as developers work with regulators over time, or on multiple projects, this interaction will benefit their working relationships by building trust and improving understanding of the environmental effects of marine energy development (Kramer et al. [3]). Increased knowledge of interactions of stressors and receptors, which is an on-going study, may eventually reduce monitoring requirements (Copping and Hemery [2]), and while any marine energy installation will involve risks to the environment, in the future these risks may be well enough understood to support the licensing, permitting, and compliance processes more efficiently.

Author Contributions: Conceptualization, W.J.P., J.R., G.K., S.K., Z.B., A.W. and C.J.; methodology, J.R., S.K., Z.B., A.W. and C.J.; formal analysis, G.K., W.J.P.; investigation, S.K., Z.B., A.W.; data curation, W.J.P.; writing-original draft preparation, W.J.P. and Z.B.; writing—review and editing, J.R., S.K., Z.B., A.W. and C.J.; visualization, W.J.P.; supervision, J.R.; project administration, Z.B.; funding acquisition, J.R. All authors have read and agreed to the published version of the manuscript.

Funding: This work completed by Sandia National Laboratories was funded by the U.S. Department of Energy's Water Power Technologies Office. Sandia National Laboratories is a multimission laboratory managed and operated by National Technology and Engineering Solutions of Sandia, LLC., a wholly owned subsidiary of Honeywell International, Inc., for the U.S. Department of Energy's National Nuclear Security Administration under contract DE-NA0003525. This paper describes objective technical results and analysis. Any subjective views or opinions that might be expressed in the paper do not necessarily represent the views of the U.S. Department of Energy or the United States Government.

Data Availability Statement: Restrictions apply to the availability of these data. Data were obtained from project developers under an agreement of anonymity and are available stripped of attribution from authors at Sandia National Laboratories.

Conflicts of Interest: The authors declare no conflict of interest.

\section{References}

1. Copping, A.E.; Freeman, M.C.; Gorton, A.M.; Hemery, L.G. Risk Retirement and Data Transferability for Marine Renewable Energy. In OES-Environmental 2020 State of the Science Report: Environmental Effects of Marine Renewable Energy Development Around the World. Report for Ocean Energy Systems (OES); Copping, A.E., Hemery, L.G., Eds.; Ocean Energy Systems: Lisbon, Portugal, 2020; pp. 262-278.

2. Copping, A.E. Marine Renewable Energy:Environmental Effects and Monitoring Strategies. In OES-Environmental 2020 State of the Science Report: Environmental Effects of Marine Renewable Energy Development around the World. Report for Ocean Energy Systems (OES); Copping, A.E., Hemery, L.G., Eds.; Ocean Energy Systems: Lisbon, Portugal, 2020; pp. 19-26.

3. Kramer, S.; Jones, C.; Klise, G.; Roberts, J.; West, A.; Barr, Z. Environmental Permitting and Compliance Cost Reduction Strategies for the MHK Industry: Lessons Learned from Other Industries. J. Mar. Sci. Eng. 2020, 8, 554. [CrossRef]

4. Copping, A.E.; Geerlofs, S.H. The Contribution of Environmental Siting and Permitting Requirements to the Cost of Energy for Marine and Hydrokinetic Devices, Reference Models \#1, \#2 and \#3; Pacific Northwest National Laboratory: Richland, WA, USA, $2011 ;$ p. 43.

5. Neary, V.S.; Lawson, M.; Previsic, M.; Copping, A.; Hallett, K.C.; Labonte, A.; Rieks, J.; Murray, D. Methodology for Design and Economic Analysis of Marine Energy Conversion (MEC) Technologies; Sandia National Laboratories: Albuquerque, NM, USA, 2014; p. 262.

6. US Army Corps of Engineers. Nationwide Permit 52: Water-Based Renewable Energy Generation Pilot Projects. Available online: https://www.swf.usace.army.mil/Portals/47/docs/regulatory/Permitting/Nationwide/NWP52TX_1.pdf?ver= C2jDaGyh4WFEJJfkfngKfg\%3D\%3D (accessed on 15 April 2021).

7. Marsland, N.; Wilson, I.; Abeyasekera, S.; Kleih, U. Combining quantitative (formal) and qualitative (informal) survey methods. In Socioeconomic Methodologies for Natural Resources Research. Best Practice Guidelines; Natural Resources Institute: Chatham, UK, 2001.

8. Busetto, L.; Wick, W.; Gumbinger, C. How to use and assess qualitative research methods. Neurol. Res. Pract. 2020, 2, 14. [CrossRef] [PubMed]

9. Gill, P.; Stewart, K.; Treasure, E.; Chadwick, B. Methods of data collection in qualitative research: Interviews and focus groups. Br. Dent. J. 2008, 204, 291-295. [CrossRef] [PubMed]

10. Barrett, D.; Twycross, A. Data collection in qualitative research. Evid.-Based Nurs. 2018, 21, 63-64. [CrossRef] [PubMed]

11. Paul, D.; Leedy Ormrod, J.E.; Johnson, L.R. Practical Research: Planning and Design, 7th ed.; SAGE Publications: Upper Saddle River, NJ, USA, 2001.

12. Williams, C. Research Methods. J. Bus. Econ. Res. 2007, 5, 65-72. Available online: https://clutejournals.com/index.php/JBER/ article/view/2532/2578 (accessed on 19 October 2020). [CrossRef] 
13. O'leary, R.; Bingham, L. The Promise And Performance Of Environmental Conflict Resolution; Resources For The Futire Press: Washington, DC, USA, 2003.

14. Copping, A.; Sather, N.; Hanna, L.; Whiting, J.; Zydlewski, G.; Staines, G.; Gill, A.; Hutchison, I.; O’Hagan, A.; Simas, T.; et al. Annex IV 2016 State of the Science Report: Environmental Effects of Marine. Renewable Energy Development Around the World; Pacific Northwest National Laboratory: Richland, WA, USA, 2016.

15. Sparling, C.E.; Seitz, A.C.; Masden, E.; Smith, K. Collision Risk for Animals Around Turbines. In OES-Environmental 2020 State of the Science Report: Environmental Effects of Marine Renewable Energy Development Around the World. Report for Ocean Energy Systems (OES); Copping, A.E., Hemery, L.G., Eds.; Ocean Energy Systems: Lisbon, Portugal, 2020; pp. $29-65$.

16. Yu, Y.H.; Jenne, D.S.; Thresher, R.; Copping, A.; Geerlofs, S.; Hanna, L. Reference Model 5: Oscillating Surge Wave Energy Converter ; National Renewable Energy Laboratory: Golden, CO, USA, 2015.

17. Bull, D.; Smith, C.; Jenne, D.; Jacob, P.; Copping, A.; Willits, S.; Fontaine, A.; Brefort, D.; Copeland, G.; Gordon, M.; et al. Reference Model 6: Oscillating Wave Energy Converter; Sandia National Laboratories: Albuquerque, NM, USA, 2014.

18. Viehman, H.A.; Zydlewski, G.B. Multi-scale temporal patterns in fish presence in a high-velocity tidal channel. PLoS ONE 2017, 12, e0176405. [CrossRef] [PubMed]

19. Polagye, B.J.; Murphy, P.; Cotter, E.; Scott, M.; Gibbs, P.; Bassett, C.; Steward, A. Adaptable monitoring package development and deployment: Lessons learned for integrated instrumentation at marine energy sites. J. Mar. Sci. Eng. 2020, 8, 553. [CrossRef] 